\title{
Quantitative Mapping of Stress Heterogeneity in Polycrystalline Alumina using Hyperspectral Fluorescence Microscopy
}

\author{
Grant A. Myers, ${ }^{1,2}$ Chris A. Michaels, ${ }^{1}$ and Robert F. Cook $^{1, *}$ \\ ${ }^{1}$ Materials Measurement Science Division, National Institute of Standards and Technology, \\ Gaithersburg, MD 20899, U.S.A. \\ ${ }^{2}$ Now at: WellDog, Gas Sensing Technology Corp., Laramie, WY 82070, U.S.A.
}

\begin{abstract}
The microstructurally-induced heterogeneous stress fields arising in a series of $\mathrm{Cr}$ doped polycrystalline alumina materials are mapped with sub-micrometer sub-grain size resolution using fluorescence microscopy. Analysis of the hyperspectral data sets generated during imaging enabled both the amplitude and position of the characteristic $\mathrm{Cr}$ R1 fluorescence peak to be determined at every pixel in an image. The peak amplitude information was used to segment the images into individual grains and grain boundary regions. The peak position information, in conjunction with measurements on single-crystal controls, was used to quantify overall stress distributions in the materials and provide stress scales for maps. The combined information enabled spatial variations in the stress fields in crystallographic axes to be mapped and compared directly with microstructural features such as grains and grain boundaries. The mean $c$-axis stresses in these materials were approximately $200 \mathrm{MPa}$ with stress distribution widths of about $70 \mathrm{MPa}$, both increasing with average grain size. Greatest variations in stress were observed at grain junctions; no trend in the stress for individual grains with grain size was observed.
\end{abstract}

Keywords: Fluorescence, Stress and strain, Alumina $\left(\alpha-\mathrm{Al}_{2} \mathrm{O}_{3}\right)$, Mapping, Image analysis Revision Submitted to Acta Materialia, January 2016

*Corresponding author: robert.cook@ nist.gov, +1 (301) 975-3207 (RFC) brombyers@gmail.com (GAM) Chris.michaels@nist.gov (CAM) 


\section{Introduction}

It has long been known that the incorporation of $\mathrm{Cr}$ into the $\mathrm{Al}_{2} \mathrm{O}_{3}$ single-crystal corundum structure generates photoluminescent sites that fluoresce with a characteristic ruby red color [14]. $\mathrm{Cr}$ is incorporated into corundum by substitutional occupation of $\mathrm{Al}$ sites with octahedral oxygen coordination. The octahedra are distorted, being somewhat extended along the body diagonal of the trigonal corundum lattice and exhibit three-fold rotational symmetry about the lattice $c$ axis. As a consequence of the octahedral geometry, the ruby fluorescence is split into a doublet consisting of two closely spaced fluorescent lines, designated R1 and R2, with energies, specified in wavenumbers, of approximately $14403 \mathrm{~cm}^{-1}$ and $14433 \mathrm{~cm}^{-1}$, respectively (the wavelengths are approximately $694 \mathrm{~nm}$ ). Early experiments showed that further distortion of the octahedral sites by application of stress to the corundum structure leads to shifts in these energies $[3,4]$, as do changes in temperature [5, 6] and composition [7], which also distort the octahedra. The intensity of the photoluminescence is strongly dependent on the polarization direction of the excitation light relative to the orientation of the octahedral sites and thus the orientation of the crystal $[1,2]$.

Measurements of the energy shifts have been applied to assess the stress state in single crystal (ruby or sapphire) and polycrystalline $\mathrm{Al}_{2} \mathrm{O}_{3}$ materials. (Transparent sapphire and translucent or opaque white polycrystalline $\mathrm{Al}_{2} \mathrm{O}_{3}$ usually contain enough trace $\mathrm{Cr}$ to make such measurements possible.) Initial applications focused on the calibration of the fluorescent line shifts with hydrostatic pressure in single crystals, such that the incorporation of small ruby chips into diamond anvil cells (DACs) enabled the pressure to be measured during high pressure experiments [8-12]. The coefficient linearly relating the shift in energy, $\Delta v$, to the pressure, $p$, was found to be similar for R1 and R2 and approximately $\Delta v\left[\mathrm{~cm}^{-1}\right]=-7.6\left[\mathrm{~cm}^{-1} / \mathrm{GPa}\right] \times p$ [GPa], broadly consistent with earlier hydrostatic $[13,14]$ and uniaxial compression measurements $[3,4,15]$. The first to apply measurement of the fluorescence shifts to polycrystalline $\mathrm{Al}_{2} \mathrm{O}_{3}$ was Grabner [16], who developed a crystallographic analysis to describe the shifts for an arbitrary stress. Grabner combined this analysis with the shift coefficients determined under uniaxial compression [3,4] to assess the residual stress state arising from thermal expansion anisotropy of the constituent corundum grains in polycrystalline $\mathrm{Al}_{2} \mathrm{O}_{3}$ : tensile and compressive stresses of order hundreds of megapascal were inferred, consistent with 
calculations and similar, later, observations $[17,18]$. The subsequent work of Clarke significantly extended the technique for applications involving polycrystalline $\mathrm{Al}_{2} \mathrm{O}_{3}$. In particular, Clarke and colleagues: verified that the shift coefficients determined in compression were also valid in tension [19, 20]; refined and extended the analysis of Grabner to enable interpretation of shifts and distributions of shifts arising from inhomogeneous stress fields [20]; refined determination of the shift coefficients as a function of crystal orientation and verified that shifts are not affected by application of shear stress [21]; and, quantified the polarization dependence of the photoluminescent R-line intensities [22].

Clarke and colleagues applied their techniques to measure stresses in fibers in matrices [2325], stresses in polycrystalline $\mathrm{Al}_{2} \mathrm{O}_{3}-\mathrm{ZrO}_{2}$ composites and laminates [26-28], and strain in wrinkled oxide coatings formed on metal surfaces [29-33]. Pezzotti and colleagues also applied the fluorescence shift methodology to measure stress distributions in $\mathrm{Al}_{2} \mathrm{O}_{3}-\mathrm{ZrO}_{2}$ composites [34] (similar to [35]), but more importantly made the first direct determination of stresses in bridging ligaments behind crack tips in large-grained polycrystalline $\mathrm{Al}_{2} \mathrm{O}_{3}[36]$ and in a series of $\mathrm{Al}_{2} \mathrm{O}_{3}$ materials with microstructures tailored with $\mathrm{Al}_{2} \mathrm{O}_{3}$ platelets $[37,38]$ and metal particles [37, 39-41] to maximize bridging. More recently, Todd and colleagues have used the methodology to measure stresses in polycrystalline $\mathrm{Al}_{2} \mathrm{O}_{3}$ and $\mathrm{Al}_{2} \mathrm{O}_{3}-\mathrm{SiC}$ composites [42], including the effects of surface grinding [43, 44], and proximity to indentations [45, 46] and high strain rate impacts [47] in polycrystalline $\mathrm{Al}_{2} \mathrm{O}_{3}, \mathrm{Al}_{2} \mathrm{O}_{3}-\mathrm{SiC}$, and $\mathrm{Al}_{2} \mathrm{O}_{3}-\mathrm{ZrO}_{2}$.

Despite the above advances and demonstrated applications, very few works have used fluorescence shift measurements to generate images (two-dimensional, 2-D, maps) of stress heterogeneity in $\mathrm{Al}_{2} \mathrm{O}_{3}$ systems. Most measurements have been single point measurements (for example [21,48]) using optical probe spot diameters of about $10 \mu \mathrm{m}$, or large area measurements with spot diameters up to $100 \mu \mathrm{m}$ encompassing and averaging the responses of many grains in polycrystals (for example, [16, 19, 20, 26-28, 35, 49]). In some cases, a series of point measurements using spot diameters of (1 to 2 ) $\mu \mathrm{m}$ have been combined to make (onedimensional) line scans. These include spot measurements about $40 \mu \mathrm{m}$ apart to assess pressure inhomogeneity in the early DAC measurements [50]. Clarke and colleagues used point measurements in (10 to 50) $\mu \mathrm{m}$ steps to generate line scans around indentations in sapphire and in bent beams of polycrystalline $\mathrm{Al}_{2} \mathrm{O}_{3}$ [19], on $\mathrm{Al}_{2} \mathrm{O}_{3}-\mathrm{ZrO}_{2}$ laminates [28], on polycrystalline $\mathrm{Al}_{2} \mathrm{O}_{3}$ fibers in an $\mathrm{Al}$ matrix [25], and around holes in polycrystalline $\mathrm{Al}_{2} \mathrm{O}_{3}$ films on metal 

epoxy matrices. The bridging ligament measurements of Pezzotti and colleagues formed line scans with (10 to 15) $\mu \mathrm{m}$ steps [36-39] and the indentation measurements of Todd and colleagues and others generated line scans with (2 to 6) $\mu \mathrm{m}$ steps $[45,46,55]$.

The first true images of stress heterogeneity in $\mathrm{Al}_{2} \mathrm{O}_{3}$ using fluorescence shifts were provided by Dauskardt and Ager [56], who constructed 2-D maps from a series of 31 one-dimensional stripes of shifts obtained with a custom-built linear detector [57]. The stripes were $2 \mathrm{~mm} \times 20$ $\mu \mathrm{m}$ centered on (30 to 50) $\mu \mathrm{m}$ steps and $16 \mu \mathrm{m}$ lateral resolution was demonstrated. A relation similar to that given above for pressure was used to infer stress from measured shifts in polycrystalline $\mathrm{Al}_{2} \mathrm{O}_{3}$ and $\mathrm{Al}_{2} \mathrm{O}_{3}-\mathrm{SiC}$ composites containing notches. Fluctuations in stress of \pm $25 \mathrm{MPa}$ over distances of $200 \mu \mathrm{m}$ were observed in the $\mathrm{Al}_{2} \mathrm{O}_{3}$. Subsequent studies using commercial Raman microprobe instruments demonstrated about $1 \mu \mathrm{m}$ lateral resolution in images of indentations in ruby (stress variations of ( -1.9 to 0.2 ) GPa inferred using the pressure relation) [58], loaded cracks in a $\mathrm{Al}_{2} \mathrm{O}_{3}$-Mo composite ( $\pm 500 \mathrm{MPa}$ inferred using the pressure relation) [40], and plan and cross-section views of oxidized alloys (( -7 to -1$)$ GPa stated) [33, 59]. A modified commercial near-field microscope was used to demonstrate $160 \mathrm{~nm}$ lateral resolution on a polycrystalline $\mathrm{Al}_{2} \mathrm{O}_{3}$, but no stress values were reported for a map with $400 \mathrm{~nm}$ pixels [60]. A custom-built wide-field instrument capable of centimeter-scale images [61] was used to image oxidized alloys with $16 \mu$ m pixels ((0 to 1.4) GPa inferred from the pressure relation) [62]. Commercial instruments have also been used to generate wide-field images of biaxially-loaded plates of sapphire with $125 \mu \mathrm{m}$ pixel spacing ((0 to 2) GPa using a biaxial stress relation) [63] and impact sites in polycrystalline $\mathrm{Al}_{2} \mathrm{O}_{3}$ with $50 \mu \mathrm{m}$ spacing ((130 to 660) $\mathrm{MPa}$ inferred from the pressure relation) [47].

Here, we build on the previous works and demonstrate 2-D stress mapping using fluorescence microscopy of polycrystalline $\mathrm{Al}_{2} \mathrm{O}_{3}$ with an emphasis on quantification of the stress variation within microstructures and between materials. Extensions to previous work include: (1) the use of $625 \mathrm{~nm}$ pixel size that enables sub-grain resolution; (2) large numbers of pixels/image that enable statistically relevant interpretations of the hyperspectral data cubes; (3) intensity-based image segmentation into individual grains and boundary regions; and, (4) explicit 
use of stress-free and composition controls in developing shift-based stress distributions and maps. The combination of (3) and (4) enables grain-by-grain investigation of stress variation. The test materials are a series of large-grain size Cr-doped polycrystalline materials; control materials are sapphire and ruby single crystals.

\section{Analysis}

The analysis relating measured fluorescence shifts in $\mathrm{Al}_{2} \mathrm{O}_{3}$ to underlying stress states is summarized here. The analysis follows the work of Ma and Clarke [20], which provided relations between shifts, stresses, and their distributions for polycrystalline $\mathrm{Al}_{2} \mathrm{O}_{3}$ with microstructurally-induced residual stress states arising from the anisotropic thermal expansion of the corundum structure. The effects of composition are also addressed.

The basis for analysis is the relation between the stress-induced scalar shift in the energy of a fluorescence line from a single crystal, $\Delta v_{\sigma}$, and the stress tensor, $\sigma_{i j}$, describing the state of deformation of the crystal [16],

$$
\Delta v_{\sigma}=\Pi_{i j} \sigma_{i j} .
$$

Here $\sigma_{i j}$ is taken in the crystal frame of reference and $\Pi_{i j}$ is the piezospectroscopic coefficient tensor in the same frame. $\Pi_{i j}$ is a symmetric second rank tensor that has symmetry properties determined by the site symmetry of the fluorescing ion. In particular, for $\mathrm{Cr}$ substituting for $\mathrm{Al}$ in a distorted octahedral site in the corundum structure, the only non-zero terms in $\Pi_{i j}$ are $\Pi_{11}, \Pi_{22}$, and $\Pi_{33}$. Hence, equation (1) becomes for corundum

$$
\Delta v_{\sigma}=\Pi_{11} \sigma_{11}+\Pi_{22} \sigma_{22}+\Pi_{33} \sigma_{33} .
$$

In principal, the three-fold rotational symmetry about the corundum 3- (or $c$-)axis should lead to equivalence of the 1- and 2- (or $a$ - and $m$-)axes, and this is what is assumed here, using conventional notation of $\Pi_{11}=\Pi_{22}=\Pi_{a}$ and $\Pi_{33}=\Pi_{c}$. For the case of hydrostatic loading $\sigma_{11}=$ $\sigma_{22}=\sigma_{33}=-p$, where $p$ is the pressure, equation (2) becomes $\Delta v_{\sigma}=-\left(2 \Pi_{a}+\Pi_{c}\right) p$, and this is the basis for shifts in the ruby $\mathrm{R}$ lines used as pressure gauges in high pressure measurements. Although $\Pi_{a}$ and $\Pi_{c}$ are different for the $\mathrm{R} 1$ and $\mathrm{R} 2$ lines $[3,4,15,21]$, the pressure sensitivity $-\left(2 \Pi_{a}+\Pi_{c}\right)$ is nearly the same for the two lines $[25,64,65]$. Here, attention will focus on the R1 line shifts, and the values $\Pi_{a}=3.26 \mathrm{~cm}^{-1} / \mathrm{GPa}$ and $\Pi_{c}=1.53 \mathrm{~cm}^{-1} / \mathrm{GPa}$ calibrated from uniaxial deformation measurements will be used [21, 22]; these values have been demonstrated to apply 
in both tension and compression, and give a pressure coefficient of $-8.05 \mathrm{~cm}^{-1} / \mathrm{GPa}$, very close to the values calibrated in DACs noted above.

In the corundum structure, the linear coefficient of thermal expansion (CTE) along the $c$ axis is greater than along the $a$-axis. Rotational symmetry about the $c$-axis requires the CTE in the $c$ - (or basal-)plane to be isotropic with the $a$-axis value. As a consequence, in the absence of constraint, on cooling a corundum structure will contract more along the $c$-axis than in the basal plane. In a dense, polycrystalline alumina material, however, the misalignment of the corundum structure from one grain to the next provides a microstructural constraint on the contractions, leading to reaction stresses. The reaction stresses are opposite in sign to the constraint-free relative CTE cooling strains such that the stress developed along the $c$-axis, $\bar{\sigma}_{c}$, averaged over many grains, is tensile, and the similarly averaged stress developed in the basal plane, $\bar{\sigma}_{a}$, is compressive:

$$
\bar{\sigma}_{c}>0, \bar{\sigma}_{a}<0 .
$$

Further, considerations of mechanical equilibrium for a polycrystal with a random distribution of corundum grain orientations show that the relationship between these two average stresses is

$$
\bar{\sigma}_{c}=-2 \bar{\sigma}_{a} .
$$

Using these average stresses allows equation (2) to be re-written to express the mean shift, $\overline{\Delta v}_{\sigma}$, measured from a random ensemble of grains:

$$
\overline{\Delta v}_{\sigma}=2 \Pi_{a} \bar{\sigma}_{a}+\Pi_{c} \bar{\sigma}_{c} .
$$

Combining equations (3) and (4) gives a relation that enables the average stress values to be determined from the mean shift,

$$
\bar{\sigma}_{c}=-2 \bar{\sigma}_{a}=\overline{\Delta v}_{\sigma} /\left(\Pi_{c}-\Pi_{a}\right) .
$$

The distributions of stresses in the $a$ and $c$ directions about the average values can be determined from the distribution of shifts, if the stresses are independent and Gaussian distributions with the same variance, $\sigma_{\mathrm{w}}^{2}$, are assumed in both directions. The probability density functions for stresses in the $a$ and $c$ directions are then given by

$$
\mathrm{d} \operatorname{Pr}\left(\sigma_{a}\right) / \mathrm{d} \sigma_{a}=\frac{1}{\left(2 \pi \sigma_{\mathrm{w}}^{2}\right)^{1 / 2}} \exp \left[-\frac{\left(\sigma_{a}-\bar{\sigma}_{a}\right)^{2}}{2 \sigma_{\mathrm{w}}^{2}}\right]
$$




$$
\mathrm{d} \operatorname{Pr}\left(\sigma_{c}\right) / \mathrm{d} \sigma_{c}=\frac{1}{\left(2 \pi \sigma_{\mathrm{w}}^{2}\right)^{1 / 2}} \exp \left[-\frac{\left(\sigma_{c}-\bar{\sigma}_{c}\right)^{2}}{2 \sigma_{\mathrm{w}}^{2}}\right] .
$$

The variance of the stress distributions is related to the variance of the shift distribution, $\left\langle\Delta v_{\sigma}^{2}\right\rangle$, by

$$
\sigma_{\mathrm{w}}^{2}=\left\langle\Delta v_{\sigma}^{2}\right\rangle /\left(4 \Pi_{a}^{2}+\Pi_{c}^{2}\right) .
$$

It is important to note that $\left\langle\Delta v_{\sigma}^{2}\right\rangle$ is given a different experimental interpretation here than in the work of Ma and Clarke. In the earlier work, $\left\langle\Delta v_{\sigma}^{2}\right\rangle^{1 / 2}$ was interpreted as the half-width of a single peak broadened by the inclusion of the responses of many grains and stress states in a single large-area measurement. Here, $\left\langle\Delta v_{\sigma}^{2}\right\rangle^{1 / 2}$ is interpreted as the standard deviation of a distribution of mean shifts representing the responses of many measurements within hyperspectral images, each containing many points within grains and many grains.

The effect of $\mathrm{Cr}$ content on the position of the $\mathrm{R} 1$ and $\mathrm{R} 2$ lines has been studied by Kaplyanskii [7], who showed that the composition-induced shift, $\Delta v_{\mathrm{C}}$, varied linearly with composition,

$$
\Delta v_{C}=\beta C_{\mathrm{m}},
$$

where $C_{\mathrm{m}}$ is composition given as the mass fraction of $\mathrm{Cr}$ in the $\mathrm{Al}_{2} \mathrm{O}_{3}: \mathrm{Cr}$ structure (noting that for small fractions $C_{\mathrm{m}}$ is $\approx 1.02 \times$ the mole fraction of $\mathrm{Cr}_{2} \mathrm{O}_{3}$ in the $\mathrm{Al}_{2} \mathrm{O}_{3}: \mathrm{Cr}_{2} \mathrm{O}_{3}$ mixture). The coefficient $\beta$ is slightly different for the two lines with, for measurements at $77 \mathrm{~K}, \beta=(96 \pm 5)$ $\mathrm{cm}^{-1}$ for the $\mathrm{R} 1$ line and $\beta=(101 \pm 5) \mathrm{cm}^{-1}$ for the $\mathrm{R} 2$ line (uncertainties cited by [7]). The shifts due to composition and stress effects are independent and additive, such that the total mean shift, $\overline{\Delta v}$, is given by the sum of equations (4) and (8):

$$
\overline{\Delta v}=\overline{\Delta v_{\sigma}}+\Delta v_{C} .
$$

The variance in the total shift is assumed to arise solely from the variance in the stress-induced shift,

$$
\left\langle\Delta v^{2}\right\rangle=\left\langle\Delta v_{\sigma}^{2}\right\rangle
$$

\section{Experimental Methods}




\subsection{Materials}

Two $\mathrm{Al}_{2} \mathrm{O}_{3}$ single-crystals were taken as stress-free reference materials. The first was Standard Reference Material 1990 (NIST, Gaithersburg, MD), in the form of single-crystal ruby spheres, $152 \mu \mathrm{m}$ in diameter with a $\mathrm{Cr}_{2} \mathrm{O}_{3}$ content of $0.42 \%$ expressed as a mole fraction of $\mathrm{Cr}_{2} \mathrm{O}_{3}$ in $\mathrm{Al}_{2} \mathrm{O}_{3}: \mathrm{Cr}_{2} \mathrm{O}_{3}$. The $c$ (00.1) lattice parameter of the spheres was certified as (1.299 $568 \pm 0.000$ 087) $\mathrm{nm}$, where the uncertainty represents an approximate $95 \%$ confidence interval. The second reference material was a single-crystal sapphire plate, $12.5 \mathrm{~mm} \times 12.5 \mathrm{~mm}$ square $\times 0.5 \mathrm{~mm}$ thick, with $c$ axis oriented perpendicular to the square face and $\mathrm{Al}_{2} \mathrm{O}_{3}$ purity $>99.99 \%$ as stated by the supplier (MTI, Richmond, CA). X-ray diffraction measurements of the 00.6 and 00.12 reflections from this plate gave equivalent 00.1 lattice spacing relative to the ruby standard of 1.00030 and 0.99975 , respectively, consistent with no significant lattice spacing or internal stress field difference between the single crystals.

A series of three polycrystalline $\mathrm{Al}_{2} \mathrm{O}_{3}$ materials was considered in detail for quantitative stress mapping. The series had been studied extensively in a previous work [66] considering the effects of microstructure, grain size in particular, on the variation of the strength and toughness properties in ceramics as a function of flaw size and crack length. Processing and microstructural details are given elsewhere [66], but in brief: The materials were infused in a porous state with a chromate solution prior to sintering at $6 \mathrm{~h}, 12 \mathrm{~h}$, and $18 \mathrm{~h}$ at $1600{ }^{\circ} \mathrm{C}$ in $\mathrm{H}_{2}$. The resulting polycrystalline materials had greater than $99.5 \%$ relative density. The mode grain sizes were approximately $10 \mu \mathrm{m}, 15 \mu \mathrm{m}$, and $20 \mu \mathrm{m}$ for the three sintering times, although the grain-size distributions were broad and some grains were as large as $60 \mu \mathrm{m}$ in all three materials. After sintering, the Cr-infused samples were pinkish in color, although less so for the longer sintering times. Sections of each material were polished for electron microprobe analysis, which showed a $\mathrm{Cr}$ content of approximately $0.025 \%$ expressed as the mass fraction of $\mathrm{Cr}$ in $\mathrm{Al}_{2} \mathrm{O}_{3}$ : $\mathrm{Cr}$. Another section of each material was cut and polished for the hyperspectral confocal fluorescence microscopy.

\subsection{Hyperspectral scanning fluorescence microscopy}


The confocal sample-scanning optical microscope was based on a custom-built design previously described [67] with the following modifications, see Fig. 1: Excitation was accomplished with a fiber-coupled helium-neon laser at $633 \mathrm{~nm}$ output through a reflective collimator (Thorlabs, Newton, NJ) and filtered with a laser-line notch filter (Semrock, Rochester, NY). The linearly polarized laser light was reflected off a long-pass filter (Semrock) in an inject-reject configuration before back-filling an oil-immersion 1.4 NA 100× objective (UPlanSApo, Olympus, Center Valley, PA) that focused the light to an estimated diffraction-limited spot 550 $\mathrm{nm}$ in diameter on the surface of the samples, which were mounted on an xyz-piezo-scan stage (NanoCube, Physik Instrumente, Karlsruhe, Germany). Epi-fluorescence from the sample was collected back through the objective, passed through the long-pass filter and focused into a single-mode optical fiber (SM600, Thorlabs) acting as the confocal aperture. It is estimated that light was collected from depths no greater than about $3 \mu \mathrm{m}$ beneath the surface (much less than the material grain size). Spectra were dispersed through a 1/2-meter spectrometer (Acton SP 2500i, Princeton Instruments, Acton, MA) with a grating pitch of 2400-groove $\mathrm{mm}^{-1}$ and imaged on a liquid- $\mathrm{N}_{2}$ cooled CCD camera (SPEC-10, Princeton Instruments), where the spectral region between $14506 \mathrm{~cm}^{-1}$ and $14317 \mathrm{~cm}^{-1}$ containing the R1 and R2 peaks was spread over the 1340 pixels of the camera (to give pixel spectral resolution of $\approx 0.14 \mathrm{~cm}^{-1}$ ). The absolute wavenumber axis for the camera was calibrated using five atomic emission reference lines that occur in this spectral range from neon, argon, and krypton lamps.

\subsection{Reference calibration and hyperspectral mapping}

Repeat fluorescence spectra from the same sample location were obtained for the two singlecrystal reference materials, the ruby sphere and the sapphire plate: 50 spectra for the ruby and 40 for the sapphire. The spectra from the ruby standard were collected with an incident power of 50 $\mu \mathrm{W}$ and an integration time for each spectrum of $1 \mathrm{sec}$. Due to the low $\mathrm{Cr}$ concentration, the spectra from the sapphire crystal required 5 min integration times with incident power of 2.5 $\mathrm{mW}$. The spectra were fit to a spectral model consisting of two peaks (R1 and R2) each with a Pearson VII line shape with fixed best-fit shape parameters for each peak, yielding the peak center wavenumbers, spectral widths, and amplitudes. 
Hyperspectral maps of the fluorescence from the polycrystalline samples were collected from regions $80 \mu \mathrm{m} \times 80 \mu \mathrm{m}$ square in 128 rows at 128 pixels per row (625 nm pixel ${ }^{-1}$ ), integrating for $0.5 \mathrm{~s} \mathrm{pixel}^{-1}$ for the 6-h and 12-h materials and $1.0 \mathrm{~s} \mathrm{pixel}^{-1}$ for the $18-\mathrm{h}$ material to achieve signal-to-noise ratios > 200:1. For each material, a total of 12 unique, randomly selected, $80 \mu \mathrm{m} \times 80 \mu \mathrm{m}$ square regions were mapped. For each spectrum in a map, a subset of 628 spectral pixels were fit in a Matlab environment (Mathworks, Natick, MA) to a dual-peak Pearson VII model with shape parameters as above, yielding peak amplitude, width, and center wavenumber parameters for R1 and R2. The peak amplitude (intensity) data were used to segment the maps into individual grains and grain-boundary regions using digital image manipulation, taking advantage of the strong polarization dependence of the fluorescence intensity $[1,2,22]$ and the different orientations of individual grains relative to the excitation polarization. The peak center data were used in combination with the single-crystal control measurements to determine peak center shift distributions that were analyzed as described above to determine mean stress and stress distributions and thence provide scales for the stress maps.

\section{Results}

\subsection{Single Crystals}

Figure 2 shows representative spectra obtained from the single crystal ruby and sapphire specimens. As the intensity of the fluorescence was much greater from the greater $\mathrm{Cr}$-content ruby, the spectrum amplitudes have been scaled for easy comparison of line position and width. Based on the relative spectral amplitudes, Cr content in the sapphire specimen can be estimated to be about $1 \times 10^{-5}$ weight fraction. For both R1 and R2, the center positions of the ruby peaks are shifted to greater wavenumbers compared with those for the sapphire peaks. Analysis of all 50 or 40 of the repeat spectra for the ruby and sapphire gave R1 peak center positions of $(14403.835 \pm 0.005) \mathrm{cm}^{-1}$ and $(14403.29 \pm 0.03) \mathrm{cm}^{-1}$ and $\mathrm{R} 2$ peak center positions of $(14433.583 \pm 0.006) \mathrm{cm}^{-1}$ and $(14432.95 \pm 0.02) \mathrm{cm}^{-1}$ for the ruby and sapphire, respectively. The values here represent experimental (mean \pm standard deviations) of the fit peak center wavenumbers. The average peak widths for the ruby and sapphire were $11.79 \mathrm{~cm}^{-1}$ and 11.00 $\mathrm{cm}^{-1}$ for $\mathrm{R} 1$ and $9.28 \mathrm{~cm}^{-1}$ and $8.86 \mathrm{~cm}^{-1}$, respectively, for $\mathrm{R} 2$; as well as a shift, the increased 

peak model to the data. Insets $A$ and $B$ in this figure are maps of the R1 peak fit-amplitude and fit-center, respectively, with pixels highlighted showing locations from which the representative spectra were collected. The peak fit-centers are indicated with vertical lines in which the smallamplitude, high-wavenumber location 1 had R1 and R2 centers at $14403.7 \mathrm{~cm}^{-1}$ and 14434.1 $\mathrm{cm}^{-1}$, respectively, and the large-amplitude, low-wavenumber location 2 had R1 and R2 centers at $14401.9 \mathrm{~cm}^{-1}$ and $14432.4 \mathrm{~cm}^{-1}$. The widths of the peaks in Fig. 3 are slightly greater than those observed for the ruby and sapphire spectra in Fig. 2, $11.9 \mathrm{~cm}^{-1}$ for R1 and $9.5 \mathrm{~cm}^{-1}$ for R2 at location 2, for example.

Figure 4 shows histograms of the R1 peak fit-center data from all 12 maps for each of the three sintered samples (sets of 196,608 spectra and peak fit-centers per sample). The mean peakfit center taken over all peak fit-centers for all samples was $14402.99 \mathrm{~cm}^{-1}$ and the standard deviation of the peak-fit center taken over all spectra for all samples was $0.5233 \mathrm{~cm}^{-1}$. The abscissa of the histograms in Fig. 3 ranges from this overall mean \pm 3 overall standard deviations, from $14401.42 \mathrm{~cm}^{-1}$ to $14404.56 \mathrm{~cm}^{-1}$; the histogram bin size was $0.05 \mathrm{~cm}^{-1}$ for a total of 64 bins. The vertical solid lines in Fig. 4 indicate the R1 peak fit-center means, $\bar{v}$, for each of the sintered samples, and these are given in Table 1. The dashed lines in Fig. 4 indicate 
consistent with the equilibrium condition, equation (3).) The mean stress values, $\bar{\sigma}_{a}$ and $\bar{\sigma}_{c}$, are comparable to those determined in similar manner for other polycrystalline $\mathrm{Al}_{2} \mathrm{O}_{3}$ materials [16$18,20,49]$, of order a few hundred megapascal. The width of the stress distributions, $\sigma_{\mathrm{w}}$, tens of megapascal, however, is significantly smaller than those inferred earlier, several hundred megapascal $[20,49]$. This difference arises as here the characteristic width of the mean peak center distribution (about $0.5 \mathrm{~cm}^{-1}$ ) of local measurements was taken to characterize the stress distribution rather than the width of a convolved peak (about $10 \mathrm{~cm}^{-1}$, similar to that of Figs. 2 and 3) arising from a broad area measurement that convoluted many local measurements [20]. Notwithstanding the reduced stress distribution widths, the $\sigma_{a}$ and $\sigma_{c}$ stress distributions overlap for each material, particularly so for the smallest mode grain size material. A consequence of this overlap is that although the mean stress values in the $c$ and $a$ directions have the expected signs, ruby - sapphire R1 peak shift adjusted for the relative Cr compositions of the sintered polycrystalline $\mathrm{Al}_{2} \mathrm{O}_{3}$ samples and the ruby, $\Delta v_{\mathrm{C}}=[0.025 /(1.02 \times 0.42)]\left(0.55 \mathrm{~cm}^{-1}\right)=0.032$ $\mathrm{cm}^{-1}$. The mean $\overline{\Delta v}_{\sigma}$ values so calculated for each sample are given in Table 1, along with the stress-induced standard deviation values $\left\langle\Delta v_{\sigma}^{2}\right\rangle^{1 / 2}=\left\langle\Delta v^{2}\right\rangle^{1 / 2}$, using equation (10).

Table 1 gives the mean stress values in the $a$ and $c$ directions within the corundum grains, $\bar{\sigma}_{a}$ and $\bar{\sigma}_{c}$, respectively, using equations (3) and (5), and the width of the distributions, $\sigma_{\mathrm{w}}$, about these mean values, using equation (7), for each of the samples. Figure 5 shows the $\sigma_{a}$ and $\sigma_{c}$ stress distributions for each material determined using equation (6) and the values in Table 1. The magnitudes of the mean stress values, $\bar{\sigma}_{a}$ and $\bar{\sigma}_{c}$, increase substantially with increasing median grain size and the widths of the distributions increase slightly with increasing median grain size. (The heights of the distributions are weighted such that

$$
\int \sigma_{a}\left(\frac{2}{3} \frac{\mathrm{d} \operatorname{Pr}\left(\sigma_{a}\right)}{\mathrm{d} \sigma_{a}}\right) \mathrm{d} \sigma+\int \sigma_{c}\left(\frac{1}{3} \frac{\mathrm{d} \operatorname{Pr}\left(\sigma_{c}\right)}{\mathrm{d} \sigma_{c}}\right) \mathrm{d} \sigma=0,
$$


positive and negative, respectively, the width of the stress distributions implies that $c$ directions in some grains will be under compressive (negative) stress and the $a$ directions in some grains will be under tensile (positive) stress.

\subsection{Polycrystalline Materials: Stress Maps}

Figure 6(upper) shows an intensity map of a region in the microstructure of the 12-h material. The strong polarization dependence of the fluorescence intensity (and to a lesser extent, the polarization-dependent efficiency of the diffraction grating in the spectrometer) provides a contrast mechanism for the differently-oriented grains and such that the grain structure of the material is apparent. Figure 6(lower) is a segmentation plot delineating grain segments and grainboundary regions based on the contrast between grains evident in Fig. 6(upper). Segmentation was accomplished manually using a variety of image processing tools in a Matlab environment, including Canny filtering, image directional gradient, image dilation, and a number of other binary-image morphological operations. The segmented grains are shown as different colors, mid-blue through dark red, in Fig. 6(lower) and the grain-boundary region is shown as dark blue. Segmentation was performed on many such maps for each material.

Figure 7 shows representative $\sigma_{c}$ stress maps for the three materials with segmented grain regions indicated by black lines; the region of the microstructure for the 12 -h material is common to both Figs. 6 and 7. The stress at a given pixel in each map is indicated by the colored scale, noting that these are different for each material. The scales for the stress maps were determined from the peak center distribution parameters given in Table 1:

$$
\sigma_{c}=\bar{\sigma}_{c}+\frac{\left(v-\bar{v}-\Delta v_{\mathrm{C}}\right)}{\left\langle\Delta v_{\sigma}^{2}\right\rangle^{1 / 2}} \sigma_{\mathrm{w}},
$$

where $v$ is the peak-center wavenumber determined at each pixel in each map. It is clear from Fig. 7 that although the stress varies from point to point in the microstructure there is not an overly strong correlation between the variation and the local grain and grain boundary structure: The grains tend to be uniformly stressed and the largest variations in stress tend to appear in isolated areas in grain boundary regions.

A more detailed assessment of the variation of stress throughout the microstructures is enabled by the identification of individual grains through the image segmentation process. Figure 
8 shows a series of $\sigma_{c}$ stress histograms for the three materials mapped in Fig. 7. The binning procedure was similar to that used in Fig. 4 (for clarity the symbols are omitted and the histograms for each material are offset). For each material, the upper histogram (in black) is the distribution of $\sigma_{c}$ stress for the entire map, the second histogram (in dark blue) is the distribution of $\sigma_{c}$ stress for the grain boundary region, and the subsequent lower histograms (in mid-blue through dark red) are the distributions of $\sigma_{c}$ stress for the individual grains identified in Fig. 7; the color coding for the histograms for the 12-h material matches the grain colors used in the segmentation map of Fig. 6. To enable comparison of the distribution of stress over smaller grains, dashed lines representing traces normalized to an amplitude of 200 counts are included. The stress scales for the histograms are aligned with the stress scales of the maps in Fig. 7. The stress distributions for individual grains are clearly distinguished in Fig. 8 and have total widths of about (50 to 75) MPa. The stress distributions for the grain boundary regions are much broader, about (150 to 200) MPa total widths, probably reflecting the larger range of octahedral bonding distortions in the disordered grain-boundary regions. Both of these quantitative assessments are of course consistent with the qualitative assessments of the pictorial maps. The sum of the individual grain and boundary region histograms gives the upper histogram; the sum of 12 such histograms gives the overall histogram for each material shown in Fig. 4 and reflected in the stress distributions of Fig. 5 with total widths of about $400 \mathrm{MPa}$.

The image segmentation process also enabled the area of individual grains to be determined. Figure 9 shows the $\sigma_{c}$ stress for individual segmented grains in each material as a function of grain area. The symbols represent the means and standard deviation limits of the stress determined within a grain (essentially analysis of the individual grain data in Fig. 8); about 100 grains were analyzed for each material. The grey bands behind the data represent the means (band midpoint) and standard deviation limits (band edges) determined for each material, as given in Table 1. Beyond noting the consistency with the above that the variation of stress within individual grains is much less than the material as a whole, there does not appear to be a trend of stress in individual grains with grain size.

\section{Discussion and Conclusions}

The results presented here demonstrate 2-D quantitative stress mapping with sub-micrometer, sub-grain size spatial resolution, considerably extending the abilities of hyperspectral 
fluorescence microscopy in polycrystalline $\mathrm{Al}_{2} \mathrm{O}_{3}$. By averaging over many image pixels within many grains, the mean crystallographic axial and basal-plane stress values determined here, $\bar{\sigma}_{c}$ and $\bar{\sigma}_{a}$, were in the ranges (90 to 220) MPa and ( -45 to -110$) \mathrm{MPa}$, respectively. Using similar analysis methods to those employed here, but applied to large-area, single-spot measurements encompassing many grains in smaller grain-size materials, somewhat larger magnitude values in the ranges (120 to 420) MPa and (-135 to -210) MPa were determined for $\bar{\sigma}_{c}$ and $\bar{\sigma}_{a}$, respectively [20,49]. As noted in those earlier studies there are clear microstructural effects that are sensed by the stress measurements: In particular, the increase in mean stress and spread in stress (Fig. 5) with increasing average grain size [49].

Other studies have also reported microstructurally-controlled intrinsic stress values in polycrystalline $\mathrm{Al}_{2} \mathrm{O}_{3}$ of order hundreds of megapascal, but beyond noting the numerical agreement there are difficulties in making more detailed comparisons: First, in many prior works, as here (Fig. 2), an (unstressed) single-crystal ruby or sapphire was measured and line shifts in the polycrystalline material relative to the single-crystal reference or control, usually from large-area measurements, were determined [16-18, 20, 26, 27, 31, 49, 61]. In many cases, however, no reference or control was provided $[19,29,55,56,59]$, or the reference was $\mathrm{Al}_{2} \mathrm{O}_{3}$ powder of unknown stress state [34, 39, 40], making absolute quantitative connection between line position measured in the polycrystalline material and stress state uncertain. In some cases, in which the $\mathrm{Al}_{2} \mathrm{O}_{3}$ microstructural stresses were not the focus, measurements on polycrystalline $\mathrm{Al}_{2} \mathrm{O}_{3}$ without applied stress [38], composite additions [42], or grinding or impact damage [43, $44,47]$ have provided appropriate relative reference values. The approximate equivalent procedure here would have taken the mean absolute peak centers, $\bar{v}$, (Fig. 4, Table 1) as the reference value for each material. (In oxidized alloy films the stresses are so large, several gigapascal, [29, 33, 59, 61, 62] that a reference measurement is hardly required.)

A second difficulty in comparing the stress measurements here with prior measurements is that several different relations have been used to determine stress values from shift values. In particular, equation (2) can be re-written as $[16,40,58,68]$

$$
\begin{aligned}
\Delta v_{\sigma} & =\left(2 \Pi_{11}+\Pi_{33}\right) \frac{\left(\sigma_{11}+\sigma_{22}+\sigma_{33}\right)}{3}+\left(\Pi_{33}-\Pi_{11}\right) \frac{\left(2 \sigma_{33}-\sigma_{11}-\sigma_{22}\right)}{3}, \\
& =\left(2 \Pi_{a}+\Pi_{c}\right) \sigma_{\mathrm{M}}+\left(\Pi_{c}-\Pi_{a}\right) \sigma_{\mathrm{S}}
\end{aligned}
$$


where the second line in equation (12) emphasizes that the first term provides a contribution to the shift from the mean stress in the structure, $\sigma_{\mathrm{M}}$, and the second term provides a contribution from the shear stress, $\sigma_{\mathrm{s}}$. For residually-stressed microstructures in mechanical equilibrium, averaged over a large number of points as in a large-area measurement, $\sigma_{\mathrm{S}} \rightarrow \bar{\sigma}_{c}$ and $\sigma_{\mathrm{M}} \rightarrow 0$. Hence the decision here to assign the inferred axial stress distribution via equation (11) to the stress scales in Figs. 7 to 9; averaged over the maps, histograms, or graphs, the distributions converge to the correct mean values. From a mapping perspective, equation (12) applies at every point in the map, but, in the absence of other information, with an unknown balance of contributions to the measured shift from $\sigma_{\mathrm{M}}$ and $\sigma_{\mathrm{S}}$ (and certainly unknown contributions from $\sigma_{11}, \sigma_{22}$, and $\left.\sigma_{33}\right)$. However, if the difference $\left(\Pi_{c}-\Pi_{a}\right)$ is small relative to the pressure coefficient $\left(2 \Pi_{a}+\Pi_{c}\right)$, (as it is for $\left.\mathrm{R} 2[3,15,21]\right)$, the shift will be dominated by the $\sigma_{\mathrm{M}}$ term in equation (12), independent of the magnitude of $\sigma_{\mathrm{S}}$. In the original work on polycrystalline $\mathrm{Al}_{2} \mathrm{O}_{3}$, Grabner reported upper bounds for $\sigma_{\mathrm{M}}$ and $\sigma_{\mathrm{S}}$, depending on which term dominated equation (12) [16], although the broad area measurements made suggest that the $\sigma_{\mathrm{S}}$ term was dominant. In subsequent broad-area measurements, the first term alone in equation (12) was used to relate measured shift to $\sigma_{M}$ as the "(average) hydrostatic stress," "mean (normal) stress," or "hydrostatic component of strain," [4, 26-30, 34, 42, 56]. In some cases in which the CTEinduced microstructural stresses were small relative to other stresses, e.g., the oxidized film on substrates systems of [29], this was a good approximation. In other cases, in which there were only CTE-induced microstructural stresses, e.g., [56], the approximation led to an assessment of nearly zero microstructural stress. In point measurements, the approximation led to the determination of $\sigma_{M}$ as the "average (local) hydrostatic stress" [36], $\sigma_{M} / 3$ as the "nearly uniaxial bridging stress," [38, 40], or bounds between $\sigma_{\mathrm{M}}$ and $\sigma_{\mathrm{M}} / 3$ (deliberately using R 2 to minimize $\left.\left(\Pi_{c}-\Pi_{\mathrm{a}}\right)[39]\right)$. In some cases, e.g., [18, 59], no stress relation is given. In all cases, it is difficult to make a direct stress comparison. Finally, in terms of mean stress relations, it is noted that the $\mathrm{Cr}$ composition of the deliberately doped polycrystalline $\mathrm{Al}_{2} \mathrm{O}_{3}$ here is greater than all used previously. Hence, although the composition correction to the shift was calculable, equations (8) and (9), it was small and probably not a significant factor in inferred stress comparisons. The difference between the $\beta$ values (equation (8)) determined at $77 \mathrm{~K}$ on single crystals (about $100 \mathrm{~cm}^{-1}$ ) [7] with those inferred here at room temperature on polycrystals (about 

where $H W H H_{\text {sapphire }}\left(=5.5 \mathrm{~cm}^{-1}\right)$ is the $\mathrm{HWHH}$ of sapphire given earlier. Equation (13) gives $\left\langle\Delta v^{2}\right\rangle^{1 / 2}=2.9 \mathrm{~cm}^{-1}$, comparable to the range of values, $(1.4$ to 3.6$) \mathrm{cm}^{-1}$, determined in prior broad area measurements on other $\mathrm{Al}_{2} \mathrm{O}_{3}$ materials [20]. These values are all much greater than the standard deviations or HWHHs (both about $0.5 \mathrm{~cm}^{-1}$ here) of the directly measured peak center distributions (Fig. 4, Table 1), and lead to much greater inferred stress distribution widths of several hundred MPa [20,49] compared with the $70 \mathrm{MPa}$ determined here. The resolution to this discrepancy lies in realizing that equation (13) should be written as

$$
\left\langle\Delta v^{2}\right\rangle=a_{1}\left(H W H H_{\text {area }}\right)^{2}-a_{2}\left(H W H H_{\text {sapphire }}\right)^{2},
$$
where $a_{1}$ and $a_{2}$ are coefficients that depend on the shape of the peak center distribution. The direct measurement of the peak center distribution via the hyperspectral imaging here enables these coefficients to be determined: For the (R1, 6-h) example, taking $a_{1}=1$ gives $a_{2}=1.26$. More detailed analyses of hyperspectral map data on a range of materials should enable better estimates of these coefficients, providing a quantitative link between imaging and broad area measurements, and significantly enhancing the quantitative nature, while still retaining the convenience, of broad area measurements.

The high spatial resolution experimental stress maps presented here may be compared directly with similar maps developed by modeling CTE-driven stresses in simulated [69] and 
experimentally determined $[70,71]$ polycrystalline $\mathrm{Al}_{2} \mathrm{O}_{3}$ grain structures. Such comparisons show both qualitative and quantitative agreement. Perhaps the most striking feature of the qualitative agreement is that the characteristic length scale for stress variation in the structures is much larger than the grain size $[69,70]$. Further points of qualitative agreement are that there is some variation in stress within grains and that the greatest variations and magnitudes of stress occur at grain junctions $[69,71]$. Quantitative points of agreement include: the magnitude of the stresses, of order a few hundred megapascal [69-71]; the variation of stress within grains is less than the variation within the entire microstructure [69]; there are overlapping distributions of $\sigma_{c}$ and $\sigma_{a}$, with $\bar{\sigma}_{c}>0$ and $\bar{\sigma}_{a}<0$ (although the magnitude of the mean values was less than observed here) [69]; and, there is no trend of individual grain stress with individual grain size and there is a much greater range of stresses within and adjacent to grain boundaries than within grains [71]. A logical next step is to use grain orientation information obtained from electron [70] or X-ray [71] diffraction to model stress development for direct grain-by-grain comparison with the luminescence-based stress mapping.

The stress distribution overlap effects inferred here depended on material sintering time. In particular, there were substantially more $\sigma_{a}$ tensile regions in the $6 \mathrm{~h}$ material than the $12 \mathrm{~h}$ and $18 \mathrm{~h}$ materials and almost no $\sigma_{c}$ compressive regions in the $12 \mathrm{~h}$ and $18 \mathrm{~h}$ materials, Fig. 5. These effects are a reflection of the microstructures of the materials. As noted above, the widths of the grain size distributions for all three materials were large and approximately constant, about $60 \mu \mathrm{m}$ [66]. The distributions themselves were skewed to smaller grain sizes, but the asymmetry decreased with increasing sintering time as reflected in the increasing mode grain sizes of $10 \mu \mathrm{m}$, $15 \mu \mathrm{m}$, and $20 \mu \mathrm{m}$, respectively. As a consequence, the magnitude of the mean stresses increased with sintering time, reflecting the increased grain sizes [17, 49], but the width of the stress distributions remained relatively constant, reflecting the constant width of the grain size distributions. The implication from Fig. 5 is that stress "reversals" from the mean stress are more likely to occur in small grains, in this case predominantly in the $6 \mathrm{~h}$ material and almost not at all in the $12 \mathrm{~h}$ and $18 \mathrm{~h}$ materials.

There are many obvious applications for hyperspectral fluorescence-based stress mapping in polycrystalline $\mathrm{Al}_{2} \mathrm{O}_{3}$, many of which have been mentioned above in the context of point or broad area measurements, including determination of: CTE anisotropy driven stress fields giving rise to microcracking [17]; ligamentary bridging stresses giving rise to toughening [37]; stress 
fields at surface contacts [45]; and, stresses in fibers in composites [51]. Others include determination of CTE mismatch driven stress fields, such as occur in microelectronic substrate or ceramic-metal seal applications. Future work will increase refinement in the quantitative nature of the mapping by extending the analysis to include information from the R2 peak shifts, both separately from the R1 shifts, in terms of equation (4) (and perhaps including non-linearity [21, $25]$ ), and in combination with the R1 shifts, in terms of mapping $\sigma_{c}$ and $\sigma_{a}$ or $\sigma_{\mathrm{M}}$ and $\sigma_{\mathrm{S}}$ (using two equations in two unknowns to split the stress field [54]). Differences in the R1 and R2 peak width [20] and polarization $[22,31,32]$ sensitivity to stress can also be used to increase the quantitative mapping capability. Finally, there is clearly more to the peak shift distributions of Fig. 4 than a single population represented by a single mean and standard deviation. The large number of points obtained by mapping (there are about $200 \mathrm{k}$ points/sample in Fig. 4) can be used to separate the distributions into separate populations, characterizing clusters of small and large grains, for example.

\section{Acknowledgements}

The authors thank W. Wong-Ng for provision of the ruby standard and M. Vaudin for performing the X-ray diffraction measurements. Certain commercial equipment, instruments, or materials are identified in this paper in order to specify the experimental procedure adequately. Such identification is not intended to imply recommendation or endorsement by the National Institute of Standards and Technology, nor is it intended to imply that the materials or equipment identified are necessarily the best available for the purpose. 


\section{References}

[1] S. Sugano, Y. Tanabe, Absorption Spectra of $\mathrm{Cr}^{3+}$ in $\mathrm{Al}_{2} \mathrm{O}_{3}$ Part A. Theoretical Studies of the Absorption Bands and Lines, J. Phys. Soc. Jpn 13 (8) (1958) 880-899.

[2] S. Sugano, I. Tsujikawa, Absorption Spectra of $\mathrm{Cr}^{3+}$ in $\mathrm{Al}_{2} \mathrm{O}_{3}$ Part B. Experimental Studies of the Zeeman Effect and Other Properties of the Line Spectra, J. Phys. Soc. Jpn 13 (8) (1958) 899-910.

[3] A.L. Schawlow, Fine Structure and Properties of Chromium Fluorescence in Aluminum and Magnesium Oxide, in: J. R. Singer (Ed.), Advances in Quantum Electronics, Columbia University Press, New York, 1961, pp. 50-64.

[4] A.A. Kaplyanskii, A.K. Przhevuskii, The Piezospectroscopic Effect in Ruby Crystals, Soviet Phys. Doklady 7 (1) (1962) 37-40.

[5] D.S. McClure, Optical Spectra of Transition-Metal Ions in Corundum, J. Chem. Phys. 36 (10) (1962) 2757-2779.

[6] D.E. McCumber, M.D. Sturge, Linewidth and Temperature Shift of the R Lines in Ruby, J. Appl. Phys. 34 (6) (1963) 1682-1684.

[7] A.A. Kaplyanskii, A.K. Przhevuskii, R.B. Rozenbaum, Concentration-Dependent Line-Shift in Optical Spectra of Ruby, Soviet Phys. Solid State 10 (8) (1969) 1864-1868.

[8] R.A. Forman, G.J. Piermarini, J.D. Barnett, S. Block, Pressure Measurement Made by the Utilization of Ruby Sharp-Line Luminescence, Science 176 (1972) 284-285.

[9] J. D. Barnett, S. Block, G. J. Piermarini, An Optical Fluorescence System for Quantitative Pressure Measurement in the Diamond-Anvil Cell, Rev. Sci. Instrum. 44 (1) (1973) 1-9.

[10] G.J. Piermarini, S. Block, J.D. Barnett, R.A. Forman, Calibration of the pressure dependence of the R 1 ruby fluorescence line to 195 kbar, J. Appl. Phys. 46 (6) (1975) 2774-2780.

[11] R.G. Munro, A scaling theory of solids under hydrostatic pressure, J. Chem. Phys. 67 (7) (1977) 3146-3150.

[12] H.K. Mao, P.M. Bell, J.W. Shaner, D.J. Steinberg, Specific volume measurements of Cu, Mo, Pd, and $\mathrm{Ag}$ and calibration of the ruby $\mathrm{R}_{1}$ fluorescence pressure gauge from 0.06 to $1 \mathrm{Mbar}$, J. Appl. Phys. 49 (6) (1978) 3276-3283.

[13] H.K. Paetzold, Über den Temperature- und Druckeinfluss auf Elecktroenterme in Kristallen, Zeitschrift für Physik 129 (2) (1951) 122-139.

[14] D.W. Langer, R.N. Euwema, Pressure Shift of the Cr Levels in $\mathrm{Al}_{2} \mathrm{O}_{3}$, J. Phys. Chem. Solids 28 (3) (1967) 463-465.

[15] E. Feher, M.D. Sturge, Effect of Stress on the Trigonal Splittings of $\mathrm{d}^{3}$ Ions in Sapphire $\left(\alpha-\mathrm{Al}_{2} \mathrm{O}_{3}\right)$, Phys. Rev. 172 (2) (1968) 244-249.

[16] L. Grabner, Spectroscopic technique for the measurement of residual stress in sintered $\mathrm{Al}_{2} \mathrm{O}_{3}, \mathrm{~J}$. Appl. Phys. 49 (2) (1978) 580-583.

[17] J.E. Blendell, R.L. Coble, Measurement of Stress Due to Thermal Expansion Anisotropy in $\mathrm{Al}_{2} \mathrm{O}_{3}$, J. Am. Ceram. Soc. 65 (3) (1982) 174-178.

[18] H. Song, R.H. French, R.L. Cable, Effect of Residual Strain on the Electronic Structure of Alumina and Magnesia, J. Am. Ceram. Soc. 72 (6) (1989) 990-994.

[19] S.E. Molis, D.R. Clarke, Measurement of Stresses Using Fluorescence in an Optical Microprobe: Stresses around Indentations in a Chromium-Doped Sapphire, J. Am. Ceram. Soc. 73 (11) (1990) 3189-3194. 
[20] Q. Ma, D.R. Clarke, Stress Measurement in Single-Crystal and Polycrystalline Ceramics Using Their Optical Fluorescence, J. Am. Ceram. Soc. 76 (6) (1993) 1433-1440.

[21] J. He, D.R. Clarke, Determination of the Piezospectroscopic Coefficients for Chromium-Doped Sapphire, J. Am. Ceram. Soc. 78 (5) (1995) 1347-1353.

[22] J. He, D.R. Clarke, Polarization Dependence of the $\mathrm{Cr}^{3+} \mathrm{R}$-Line Fluorescence from Sapphire and Its Application to Crystal Orientation and Piezospectroscopic Measurement, J. Am. Ceram. Soc. 80 (1) (1997) 69-78.

[23] Q. Ma, D.R. Clarke, Measurement of Residual Stresses in Sapphire Fiber Composites Using Optical Fluorescence, Acta metall. Mater. 41 (6) (1993) 1817-1823.

[24] Q. Ma, L.C. Liang, D.R. Clarke, J.W. Hutchinson, Mechanics of the Push-Out Process from In Situ Measurement of the Stress Distribution Along Embedded Sapphire Fibers, Acta metall. Mater. 42 (10) (1994) 3299-3308.

[25] J. He, I.J. Beyerlein, D.R. Clarke, Load transfer from broken fibers in continuous fiber $\mathrm{Al}_{2} \mathrm{O}_{3}-\mathrm{Al}$ composites and dependence on local volume fraction, J. Mech. Phys. Solids 47 (3) (1999) 465-502.

[26] V. Sergo, D.R. Clarke, W. Pompe, Deformation Bands in Ceria-Stabilized Tetragonal Zirconia/Alumina: I, Measurement of Internal Stresses, J. Am. Ceram. Soc. 78 (3) (1995) 633-640.

[27] V. Sergo, D.R. Clarke, Deformation Bands in Ceria-Stabilized Tetragonal Zirconia/Alumina: II, Stress-Induced Aging at Room Temperature, J. Am. Ceram. Soc. 78 (3) (1995) 641-644.

[28] V. Sergo, D.M. Lipkin, G. De Portu, D.R. Clarke, Edge Stresses in Alumina/Zirconia Laminates, J. Am. Ceram. Soc. 80 (7) (1997) 1633-1638.

[29] X.-Y. Gong, D.R. Clarke, On the Measurement of Strain in Coatings Formed on a Wrinkled Elastic Substrate, Oxidation Mater. 50 (5/6) (1998) 355-376.

[30] X. Peng, N. Sridhar, D.R. Clarke, The stress distribution around holes in thermal barrier coatings, Mater. Sci. Engin. A 380 (1-2) (2004) 208-214.

[31] S.H. Margueron, D.R. Clarke, The use of polarization in the piezospectroscopic determination of the residual stresses in polycrystalline alumina films, Acta Mater. 54 (20) (2006) 5551-5557.

[32] D.J. Gardiner, M. Bowden, S.H. Margueron, D.R. Clarke, Use of polarization in imaging the residual stresses in polycrystalline alumina films, Acta Mater. 55 (10) (2007) 3431-3436.

[33] D.R. Clarke, D.J. Gardiner, Recent advances in piezospectroscopy, Int. J. Mater. Res. 98 (8) (2007) 756-762.

[34] V. Sergo, G. Pezzotti, O. Sbaizero, T. Nishida, Grain Size Influence on Residual Stresses in Alumina/Zirconia Composites, Acta Mater. 46 (5) (1998) 1701-1710.

[35] Q. Ma, W. Pompe, J.D. French, D.R. Clarke, Residual Stresses in $\mathrm{Al}_{2} \mathrm{O}_{3}-\mathrm{ZrO}_{2}$ Composites: A Test of Stochastic Stress Models, Acta metall. mater. 42 (5) (1994) 1673-1681.

[36] G. Pezzotti, O. Sbaizero, V. Sergo, N. Muraki, K. Maruyama, T. Nishida, In Situ Measurements of Frictional Bridging Stresses in Alumina Using Fluorescence Spectroscopy, J. Am. Ceram. Soc. 81 (1) (1998) 187-192.

[37] G. Pezzotti, In situ Study of Fracture Mechanisms in Advanced Ceramics using Fluorescence and Raman Microprobe Spectroscopy, J. Raman Spectrosc. 30 (10) (1999) 867-875.

[38] G. Pezzotti, H. Okuda, N. Muraki, T. Nishida, In Situ Determination of Bridging Stresses in $\mathrm{Al}_{2} \mathrm{O}_{3} /$ $\mathrm{Al}_{2} \mathrm{O}_{3}$-platelet Composites by Fluorescence Spectroscopy, J. Eur. Ceram. Soc. 19 (5) (1999) 601608. 
[39] G. Pezzotti, H. Suenobu, T. Nishida, O. Sbaizero, Measurement of Microscopic Bridging Stresses in an Alumina/Molybdenum Composite by In Situ Fluorescence Spectroscopy, J. Am. Ceram. Soc. 82 (5) (1999) 1257-1262.

[40] G. Pezzotti, W.H. Müller, Micromechanics of fracture in a ceramic/metal composite studied by in situ fluorescence spectroscopy I: Foundations and stress analysis, Continuum Mech. Thermodyn. 14 (1) (2002) 113-126.

[41] G. Pezzotti, W.H. Müller, Micromechanics of fracture in a ceramic/metal composite studied by in situ fluorescence spectroscopy II: Fracture mechanics analysis, Continuum Mech. Thermodyn. 16 (5) (2004) 471-479.

[42] J.L. Ortiz Merino, R.I. Todd, Thermal microstress measurements in $\mathrm{Al}_{2} \mathrm{O}_{3} / \mathrm{SiC}$ nanocomposites by $\mathrm{Cr}^{3+}$ fluorescence microscopy, J. Eur. Ceram. Soc. 23 (11) (2003) 1779-1783.

[43] S. Guo, R.I. Todd, $\mathrm{Cr}^{3+}$ microspectroscopy measurements and modelling of local variations in surface grinding stresses in polycrystalline alumina, J. Eur. Ceram. Soc. 30 (12) (2010) 2533-2545.

[44] S. Guo, A. Limpichaipanit, R.I. Todd, High resolution optical microprobe investigation of surface grinding stresses in $\mathrm{Al}_{2} \mathrm{O}_{3}$ and $\mathrm{Al}_{2} \mathrm{O}_{3} / \mathrm{SiC}$ nanocomposites, J. Eur. Ceram. Soc. 31 (1-2) (2011) $97-$ 109.

[45] S. Guo, R.I. Todd, Quantitative optical fluorescence microprobe measurements of stresses around indentations in $\mathrm{Al}_{2} \mathrm{O}_{3}$ and $\mathrm{Al}_{2} \mathrm{O}_{3} / \mathrm{SiC}$ nanocomposites: The influence of depth resolution and specimen translucency, Acta Mater. 59 (7) (2011) 2637-2647.

[46] S. Huang, J.G.P. Binnera, B. Vaidhyanathana, R.I. Todd, Quantitative analysis of the residual stress and dislocation density distributions around indentations in alumina and zirconia toughened alumina (ZTA) ceramics, J. Eur. Ceram. Soc. 34 (3) (2014) 753-763.

[47] C.E.J. Dancer, H.M. Curtis, S.M. Bennett, N. Petrinic, R.I. Todd, High strain rate indentationinduced deformation in alumina ceramics measured by $\mathrm{Cr}^{3+}$ fluorescence mapping, J. Eur. Ceram. Soc. 31 (13) (2011) 2177-2187.

[48] S. Gallops, T. Fett, J.W. Ager III, J.J. Kruzic, Fatigue threshold R-curves predict small crack fatigue behavior of bridging toughened materials, Acta Mater. 59 (20) (2011) 7654-7661.

[49] Q. Ma, D.R. Clarke, Piezospectroscopic Determination of Residual Stresses in Polycrystalline Alumina, J. Am. Ceram. Soc. 77 (2) (1994) 298-302.

[50] G.J. Piermarini, S. Block, and J.D. Barnett, Hydrostatic limits in liquids and solids to $100 \mathrm{kbar}$, J. Appl. Phys. 44 (12) (1973) 5377-5382.

[51] R.B. Yallee, M.C. Andrews, R.J. Young, Fragmentation in alumina fibre reinforced epoxy model composites monitored using fluorescence spectroscopy, J. Mater. Sci. 31 (13) (1996) 3349-3359.

[52] J.D. Belnap, D.K. Shetty, Micromechanics of crack bridging in sapphire/epoxy composites, Composites Sci. Technol. 58 (11) (1998) 1763-1773.

[53] J.D. Belnap, D.K. Shetty, Interfacial properties of sapphire/epoxy composites: Comparison of fluorescence spectroscopy and fiber push-in techniques, Composites Sci. Technol. 65 (11-12) (2005) 1851-1860.

[54] R. Sinclair, R.J. Young, R.D.S. Martin, Determination of the axial and radial fibre stress distributions for the Broutman test, Composites Sci. Technol. 64 (2) (2004) 181-189.

[55] H.Z. Wu, S.G. Roberts, B. Derby, Residual stress distributions around indentations and scratches in polycrystalline $\mathrm{Al}_{2} \mathrm{O}_{3}$ and $\mathrm{Al}_{2} \mathrm{O}_{3} / \mathrm{SiC}$ nanocomposites measured using fluorescence probes, Acta Mater. 56 (1) (2008) 140-149. 
[56] R.H. Dauskardt, J.W. Ager III, Quantitative stress mapping in alumina composites by optical fluorescence imaging, Acta Mater. 44 (2) (1996) 625-641.

[57] D.K. Veirs, J.W. Ager III, E.T. Loucks, G.M. Rosenblatt, Mapping materials properties with Raman spectroscopy utilizing a 2-D detector, Appl. Optics 29 (33) (1990) 4969-4980.

[58] G.K. Banini, M.M. Chaudhri, T. Smith, I.P. Hayward, Measurement of residual stresses around Vickers indentations in a ruby crystal using a Raman luminescence microscope, J. Phys. D: Appl. Phys. 34 (22) (2001) L122-L124.

[59] D.B. Hovis, A.H. Heuer, Confocal photo-stimulated microspectroscopy (CPSM) - residual stress measurements in Al2O3 using confocal microscopy, Scripta Mater. 53 (3) (2005) 347-349.

[60] T. Tomimatsu, Y. Kagawa, D.R. Clarke, Determination of the R-line luminescence spatial resolution of a near-field optical spectroscopy system for piezospectroscopy, J. Appl. Phys. 101 (12) (2007) 123527-1-8.

[61] J.B. Abbiss and B. Heeg, Imaging piezospectroscopy, Rev. Sci. Instrum. 79 (12) (2008) 123105-19.

[62] B. Heeg, V.K. Tolpygo, D.R. Clarke, Damage Evolution in Thermal Barrier Coatings with Thermal Cycling, J. Am. Ceram. Soc. 94 [S1] (2011) S112-S119.

[63] K. Wan, W. Zhu, G. Pezzotti, Methods of piezo-spectroscopic calibration of thin-film materials: I. Ball-on-ring biaxial flexure, Meas. Sci. Technol. 17 (1) (2006) 181-190.

[64] R.G. Munro, G. J. Piermarini, S. Block, and W.B. Holzapfel, Model lineshape analysis for the ruby R lines used for pressure measurement, J. Appl. Phys. 57 (2) (1985) 165-169.

[65] D.D. Ragan, D.R. Clarke, and D. Schiferl, Silicone fluid as a high-pressure medium in diamond anvil cells, Rev. Sci. Instrum. 67 (2) (1996) 494-496.

[66] R.F. Cook, E.G. Liniger, R.W. Steinbrech, F. Deuerler, Sigmoidal Indentation-Strength Characteristics of Polycrystalline Alumina, J. Am. Ceram. Soc. 77 (2) (1994) 303-314.

[67] G.A. Myers, S.S. Hazra, M.P. de Boer, C.A. Michaels, S.J. Stranick, R.P. Koseski, R.F. Cook, F.W. DelRio, Appl. Phys. Letters 104 (19) (2014) 191908-1-5.

[68] C.P. Ostertag, L.H. Robins, L.P. Cook, Cathodoluminescence Measurement of Strained Alumina Single Crystals, J. Eur. Ceram. Soc. 7 (1991) 109-116.

[69] A. Zimmermann, E.R. Fuller Jr, J. Rödel, Residual Stress Distributions in Ceramics, J. Am. Ceram. Soc. 82 (11) (1999) 5155-5160.

[70] V.R. Vedula, S.J. Glass, D.M. Saylor, G.S. Rohrer, W.C. Carter, S.A. Langer, E.R. Fuller Jr, Residual-Stress Predictions in Polycrystalline Alumina, J. Am. Ceram. Soc. 84 (12) (2001) 29472954.

[71] D. Gonzalez, A. King, M. Mostafavi, P. Reischig, S. Rolland du Roscoat, W. Ludwig, J. Quinta da Fonseca, P.J. Withers, T.J. Marrow, Three-dimensional observation and image-based modelling of thermal strains in polycrystalline alumina, Acta Mater. 61 (20) (2013) 7521-7533. 


\section{Tables}

Table 1. Microstructural, R1 fluorescence, and stress distribution properties of aluminas

\begin{tabular}{|c|c|c|c|c|c|c|c|}
\hline $\begin{array}{l}\text { Sintering } \\
\text { time } \\
\text { (h) }\end{array}$ & $\begin{array}{l}\text { Mode } \\
\text { grain } \\
\text { size } \\
(\mu \mathrm{m})\end{array}$ & $\begin{array}{l}\text { Mean } \\
\text { peak- } \\
\text { center } \\
\text { position, } \\
\bar{v} \\
\left(\mathrm{~cm}^{-1}\right)\end{array}$ & $\begin{array}{l}\text { Stress- } \\
\text { induced } \\
\text { mean } \\
\text { shift, } \\
\overline{\Delta v}_{\sigma} \\
\left(\mathrm{cm}^{-1}\right)\end{array}$ & $\begin{array}{l}\text { Standard } \\
\text { deviation } \\
\text { of mean } \\
\text { shift, } \\
\left\langle\Delta v_{\sigma}^{2}\right\rangle^{1 / 2} \\
\left(\mathrm{~cm}^{-1}\right)\end{array}$ & $\begin{array}{l}\text { Mean } \\
\text { stress in } \\
c- \\
\text { direction, } \\
\bar{\sigma}_{c} \\
(\mathrm{MPa})\end{array}$ & $\begin{array}{l}\text { Mean } \\
\text { stress in } \\
a \text { - } \\
\text { direction, } \\
\bar{\sigma}_{a} \\
(\mathrm{MPa})\end{array}$ & $\begin{array}{l}\text { Stress } \\
\text { distribution } \\
\text { width, } \\
\sigma_{\mathrm{w}} \\
(\mathrm{MPa})\end{array}$ \\
\hline 6 & 10 & 14403.16 & -0.162 & 0.46 & 93.7 & -46.8 & 68.7 \\
\hline 12 & 15 & 14402.97 & -0.352 & 0.47 & 203.5 & -101.8 & 70.2 \\
\hline 18 & 20 & 14402.93 & -0.392 & 0.51 & 226.6 & -113.3 & 76.2 \\
\hline
\end{tabular}




\section{Figure Captions}

Fig. 1. Schematic diagram of optical system used to map fluorescence in polycrystalline $\mathrm{Al}_{2} \mathrm{O}_{3}$. $\mathrm{ALT}=$ achromatic lens telescope, $\mathrm{BS}=$ beamsplitter, $\mathrm{CCD}=$ charge coupled device, $\mathrm{CUF}=$ clean-up filter, $\mathrm{FC}=$ fiber coupler, $\mathrm{FI}=$ Faraday isolator, $\mathrm{FL}=$ field lens, $\mathrm{FS}=$ field stop, $\mathrm{HWP}=$ half-wave plate, $\mathrm{L}=$ lens, $\mathrm{M}=$ mirror, $\mathrm{Pol}=$ polarizer, $\mathrm{REF}=$ Raman edge filter, $\mathrm{SMF}=$ single mode fiber, $\mathrm{TL}=$ tube lens, $\mathrm{WL}=$ white light

Fig. 2. Fluorescence spectra of $\mathrm{Al}_{2} \mathrm{O}_{3}$ sapphire and ruby single crystals used as controls for fluorescence shift measurements. The characteristic R1 and R2 peaks associated with $\mathrm{Cr}$ substitution for $\mathrm{Al}$ are labelled. The ruby spectrum has been scaled down (by $\approx 10^{-3}$ ) so as to make clear the shifts in both peaks relative to sapphire associated with increased $\mathrm{Cr}$ content.

Fig. 3. Fluorescence spectra obtained from two different locations in a polycrystalline $\mathrm{Al}_{2} \mathrm{O}_{3}$ material (6-h sintering time). The characteristic R1 and R2 peaks are labelled and both amplitudes and positions are changed for different locations in the microstructure, indicating a change in crystal orientation and stress state, respectively. Inset A is a peak amplitude map, inset $\mathrm{B}$ is a peak position map, and the locations 1 and 2 are indicated.

Fig. 4. Histograms of the R1 fluorescence peak center positions for all three polycrystalline $\mathrm{Al}_{2} \mathrm{O}_{3}$ materials (sintering times indicated). The vertical lines indicate the means and standard deviations of the individual histograms.

Fig. 5. Weighted stress distributions for all three polycrystalline $\mathrm{Al}_{2} \mathrm{O}_{3}$ materials using equations (3), (6), and the parameters in Table 1 . The crystallographic axial stresses, $\sigma_{c}$, are predominantly tensile and the crystallographic basal-plane stresses, $\sigma_{a}$, are predominantly compressive.

Fig. 6. (Upper) Fluorescence peak center amplitude map of a polycrystalline $\mathrm{Al}_{2} \mathrm{O}_{3}$ material (12$\mathrm{h}$ sintering time); the microstructural contrast mechanism is the polarization dependence of the fluorescence intensity for the differently-oriented grains. (Lower) A segmentation map of the microstructure using the amplitude map and digital image processing; the different grains are shown in different colors as is the grain-boundary region.

Fig. 7. Microstructure and stress maps for all three polycrystalline $\mathrm{Al}_{2} \mathrm{O}_{3}$ materials (sintering times indicated). The microstructures were determined by analysis of fluorescence peak center amplitude maps; the stresses were determined by analysis of fluorescence peak center shift maps. Note that the scales for the crystallographic axial stresses, $\sigma_{c}$, are different for the three materials. Fig. 8. Stress histograms for all three polycrystalline $\mathrm{Al}_{2} \mathrm{O}_{3}$ materials (sintering times indicated) from the maps of Fig. 7. The upper histogram is for an entire map; the lower histograms, shown in different colors, are for the grain boundary region and individual grains.

Fig. 9. Plots of crystallographic axial stresses, $\sigma_{c}$, for all three polycrystalline $\mathrm{Al}_{2} \mathrm{O}_{3}$ materials (sintering times indicated) as a function of grain area. Symbols represent the means and standard deviations of stress within individual grains; the shaded bands represent the means and standard deviations of stress for a material. 
FIGURE 1

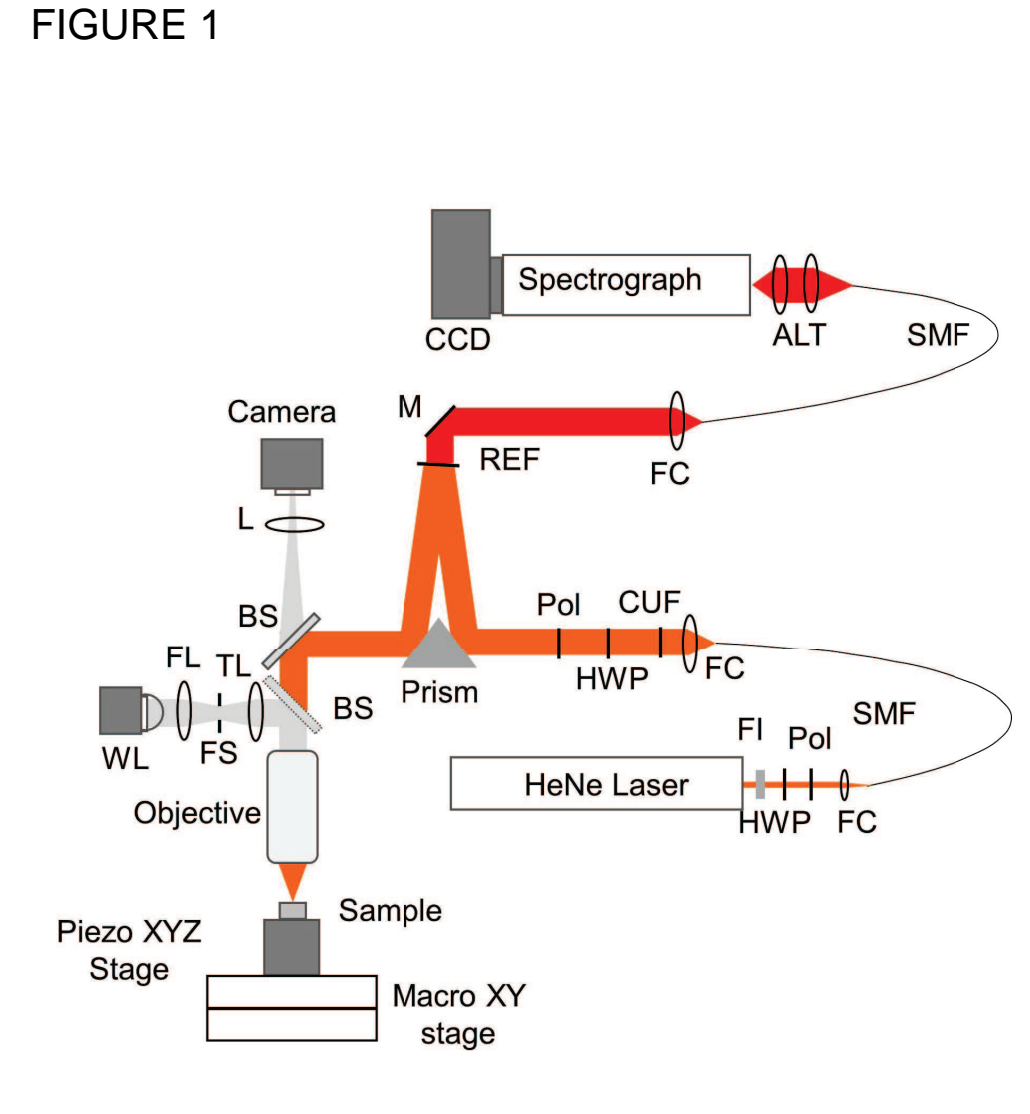

Figure(s)

FIGURE 1

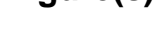

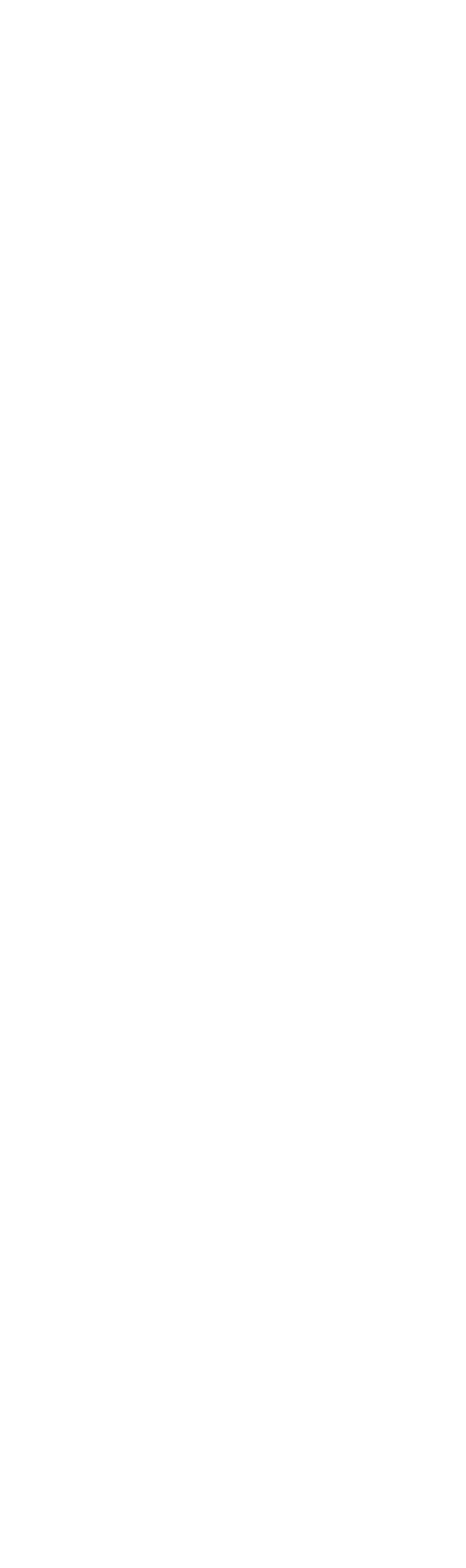


FIGURE 2

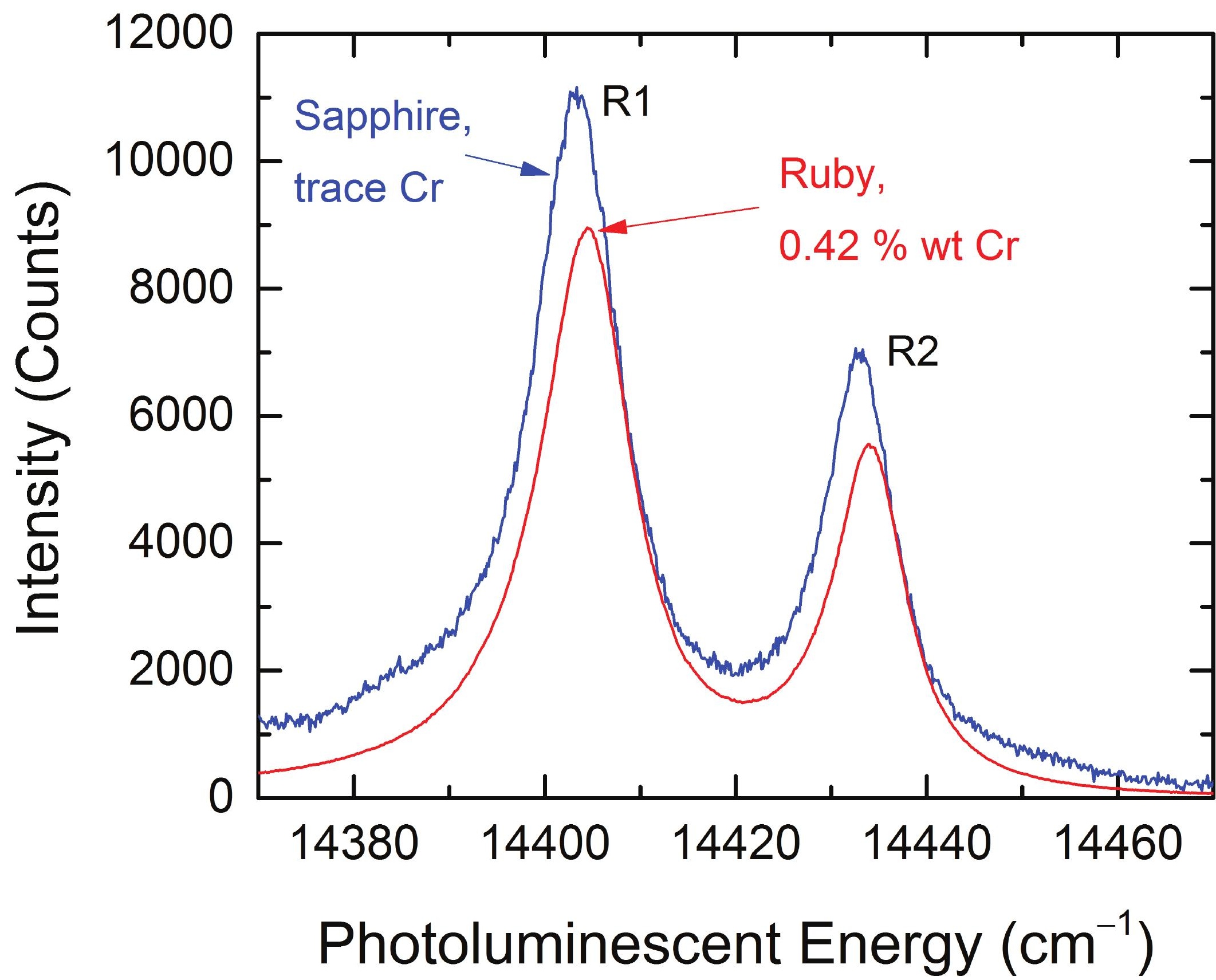


FIGURE 3

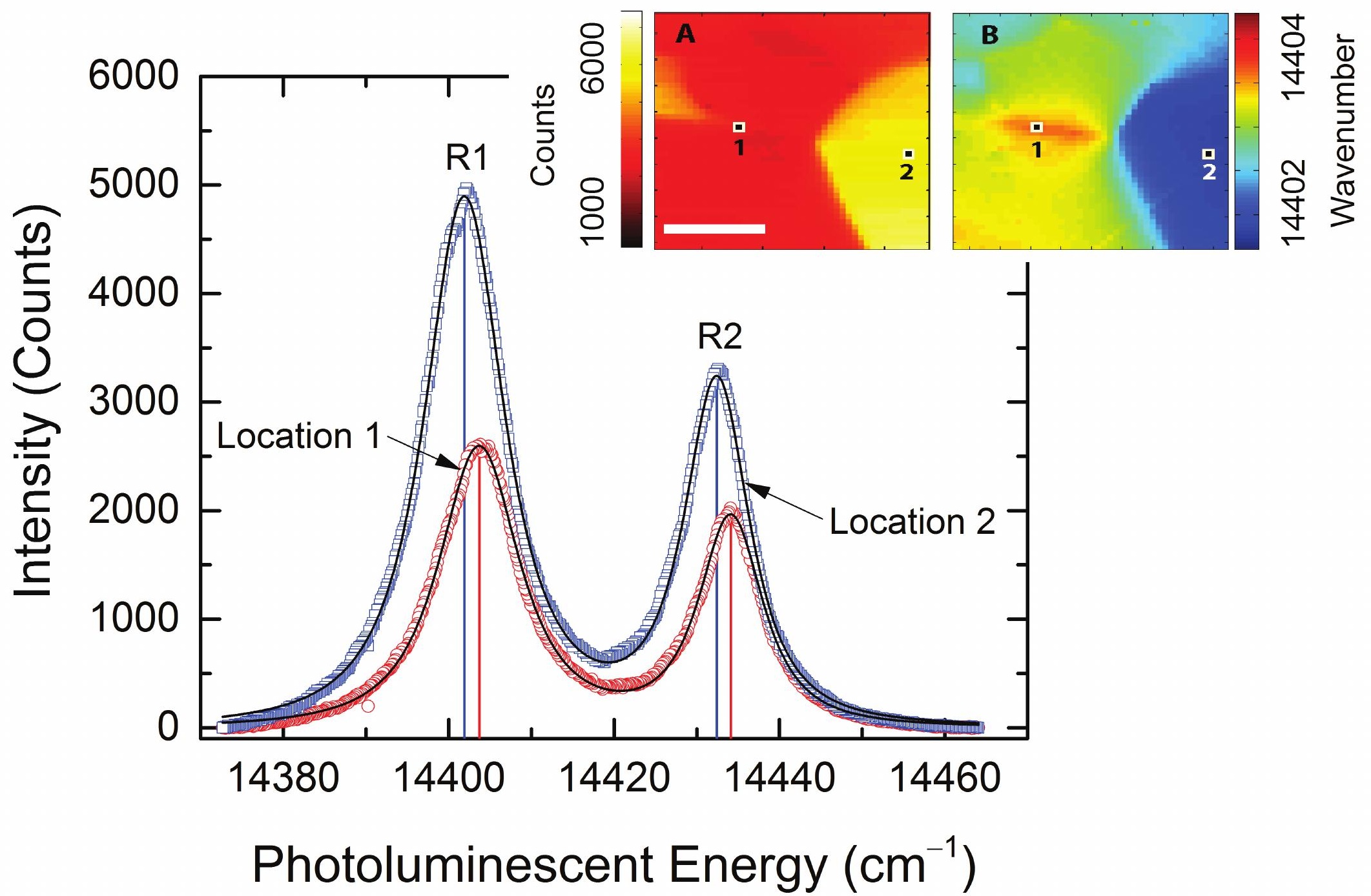


FIGURE 5

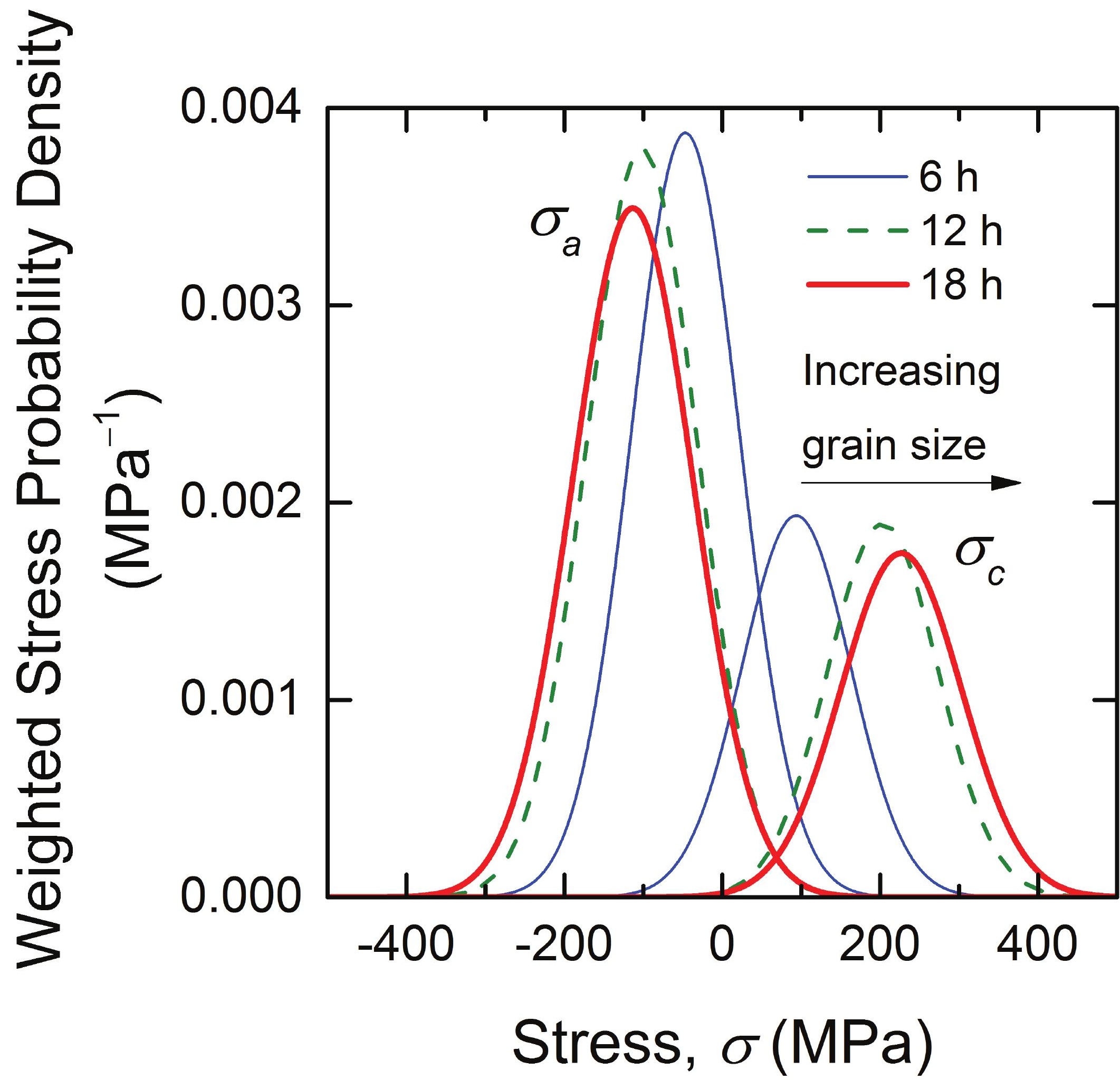


Fit Amplitude (counts $\mathrm{s}^{-1}$ )

$2000 \quad 4000 \quad 6000$

FIGURE 6

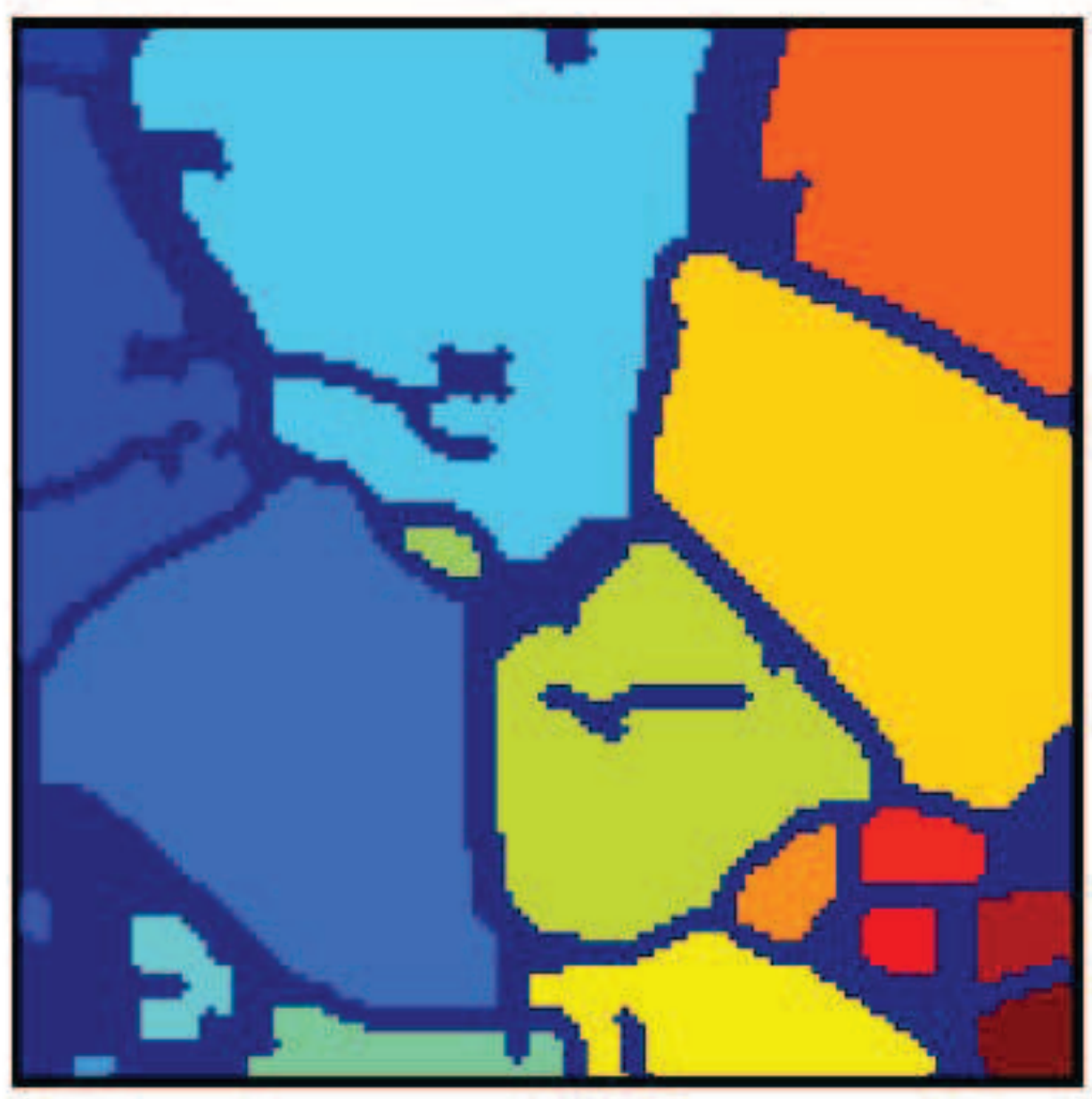



